\title{
Reliability of Mixed-Heterojunction Organic Photovoltaics Grown via Organic Vapor Phase Deposition
}

\author{
Byeongseop Song, Quinn C. Burlingame, Kyusang Lee, and Stephen R. Forrest**
}

Recent improvements in small molecular-weight organic photovoltaics (OPVs) have been realized by controlling thinfilm morphology down to the nanometer scale. ${ }^{[1-4]}$ Morphology has been found to influence device efficiencies, ${ }^{[5-7]}$ operational lifetimes, ${ }^{[8-10]}$ and failure mechanisms..$^{[11,12]}$ One method to effectively control the film morphology is via growth by organic vapor phase deposition (OVPD), [13-15] where deposition occurs in the presence of a hot, inert carrier gas that provides extra energy for organic molecules to find an equilibrium configuration as they adsorb onto the substrate. This is in contrast to conventional vacuum thermal evaporation (VTE), where molecules follow ballistic trajectories from the source to the substrate, affording them little opportunity to find a lowest energy site before being buried by subsequently arriving molecules. ${ }^{[16]}$ Also, OVPD has the advantages of high material utilization efficiency, ${ }^{[17,18]}$ scalability for uniform growth over large substrates, ${ }^{[19,20]}$ and enhanced device lifetime. ${ }^{[21]}$ In this work, we show that morphological changes over time in a bathophenanthroline (Bphen) cathode blocking layer used in fullerene-based OPVs strongly impact device reliability and that these changes are significantly reduced when the underlying active region is grown by OVPD versus VTE.

The wide energy gap Bphen has often been used in organic light emitting diodes (OLEDs), ${ }^{[22,23]}$ and $\mathrm{OPVS}^{[24,25]}$ as an optical spacer and exciton blocking layer proximal to the cathode contact. ${ }^{[26,27]}$ However, devices containing Bphen suffer from morphological instabilities ${ }^{[28,29]}$ resulting from its low glass transition temperature of $62{ }^{\circ} \mathrm{C} .{ }^{[30]}$ When deposited onto a tetraphenyl-dibenzoperiflanthene (DBP): $\mathrm{C}_{70}$ mixed active region grown by VTE, the morphological transformation of Bphen is found to significantly reduce the open-circuit voltage $\left(V_{\mathrm{OC}}\right)$ from $0.91 \pm 0.01$ to $0.52 \pm 0.01 \mathrm{~V}$ after aging at $50 \pm 5{ }^{\circ} \mathrm{C}$ for $250 \mathrm{~h}$ under simulated air mass 1.5 global (AM 1.5G) solar illumination. The decrease in $V_{\mathrm{OC}}$ results in the reduction of the power conversion efficiency (PCE) from $6.0 \% \pm 0.2 \%$ to $3.1 \%$

B. Song, Q. C. Burlingame, K. Lee, Prof. S. R. Forrest Department of Electrical Engineering and Computer Science

University of Michigan

Ann Arbor, MI 48109, USA

E-mail: stevefor@umich.edu

Prof. S. R. Forrest

Department of Physics

Materials Science and Engineering

University of Michigan

Ann Arbor, MI 48109, USA

DOI: 10.1002/aenm.201401952 $\pm 0.2 \%$. In addition, the morphological degradation results in electrical shorts across the devices, greatly reducing device yield from $93 \%$ to $63 \%$ for VTE-optimized devices. In contrast, the rougher, nanocrystalline surfaces of the $\mathrm{DBP}: \mathrm{C}_{70}$ active layers grown by OVPD effectively pin the overlying amorphous Bphen, thereby preventing morphological changes. Hence, OPVs grown by OVPD have the highest PCE $=6.7 \% \pm 0.2 \%$, and experience little change in $V_{\mathrm{OC}}$, PCE or device yield when similarly aged.

Atomic force (AFM) and optical microscope images of an $8 \mathrm{~nm}$ thick Bphen layer on a 1:10 (by vol.) DBP: $\mathrm{C}_{70}$ active layer $(60 \mathrm{~nm}$ thick for VTE-grown or $200 \mathrm{~nm}$ thick for OVPDgrown devices) are shown in Figure 1. Active layer thicknesses were individually optimized for each growth technique, with the nanocrystalline OVPD active layer grown thicker due to its higher conductivity than the amorphous layers grown by VTE. ${ }^{[31]}$ Figure $1 \mathrm{a}-\mathrm{d}$ shows images of a Bphen cap on a VTEgrown active layer after $0,12,25$, and $75 \mathrm{~h}$ aging, respectively, under simulated 1 sun intensity, AM 1.5G solar illumination (see Experimental Section). The initial Bphen surface has a root-mean-square (RMS) roughness of $0.4 \pm 0.1 \mathrm{~nm}$, followed by spherulite growth appearing within $25 \mathrm{~h}$ (Figure 1c,d). In contrast, the Bphen on the relatively rough nanocrystalline OVPD-grown active layer (RMS $=1.2 \pm 0.2 \mathrm{~nm}$, Figure 1e) becomes only marginally rougher, to RMS $=2.2 \pm 0.4 \mathrm{~nm}$, over this same period (Figure 1f,g). There are only a very few regions of local crystallization after $75 \mathrm{~h}$ (Figure $1 \mathrm{~h}$ ). The active layer surface itself has an RMS roughness of $0.8 \pm$ $0.2 \mathrm{~nm}$ for VTE and $4.1 \pm 0.2 \mathrm{~nm}$ for OVPD, neither of which changed after $75 \mathrm{~h}$. Hence, we conclude that all morphological changes occur only in the Bphen overlayer. This suggests that the initially rough OVPD-grown surface pins the morphology of Bphen, whereas the smooth VTE-grown active layer does not.

X-ray diffraction (XRD) measurements of the $100 \mathrm{~nm}$ thick VTE- and OVPD-grown DBP: $C_{70}$ layers on sapphire are shown in Figure 2a. The peak at $10.26^{\circ} \pm 0.03^{\circ}$ corresponds to diffraction from the (111) plane of the face-centered-cubic (fcc) crystal structure of $C_{70},{ }^{[32]}$ which is only apparent for the OVPD-grown layer (curve II, Figure 2a), indicative of its nanocrystalline morphology. In contrast, the diffraction pattern of the VTE-grown active layer is featureless due to its amorphous structure (curve I, Figure 2a). ${ }^{[31]}$ Following aging for $75 \mathrm{~h}$, the XRD measurements of a $50 \mathrm{~nm}$ thick Bphen on a $100 \mathrm{~nm}$ thick DBP: $C_{70}$ layer grown by VTE show the emergence of a narrow, strong reflection at $8.37^{\circ} \pm 0.03^{\circ}$ corresponding to a crystal plane spacing of $d_{002}=10.55 \pm 0.04 \AA$ of the orthorhombic Bphen lattice (curve I, Figure 2b), ${ }^{[33]}$ whereas the Bphen peak on the OVPDgrown layer is broad and weak (curve II, Figure 2b). From the 

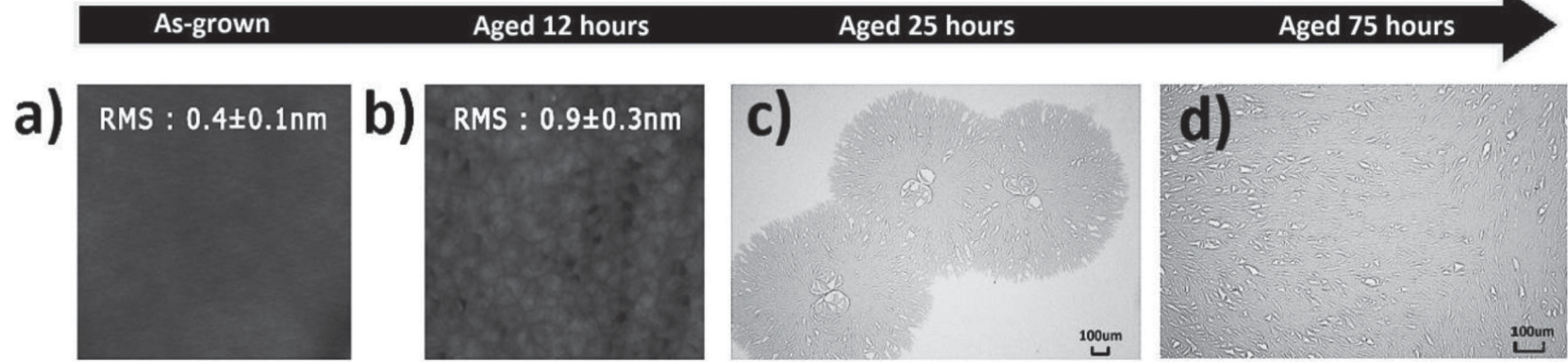

e)
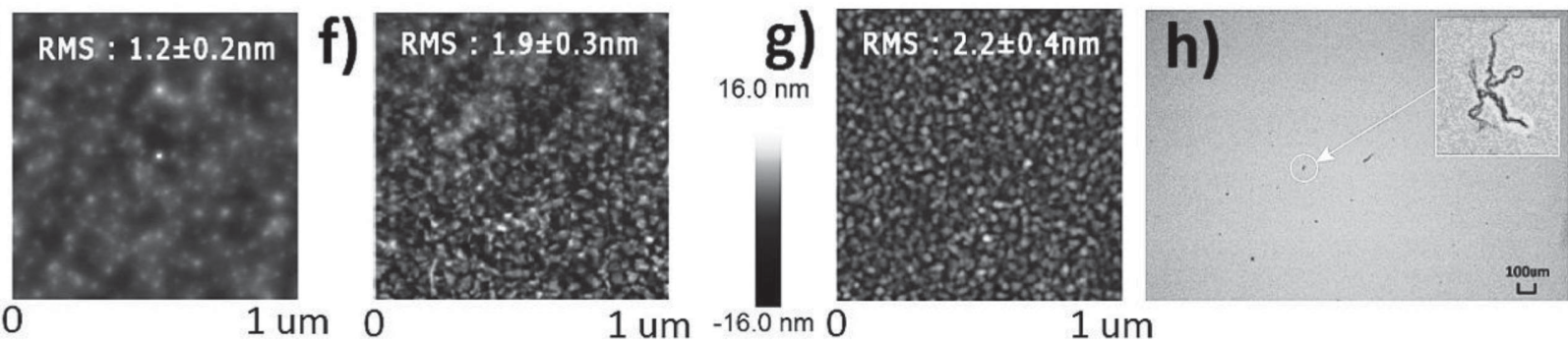

Figure 1. a) Atomic force (AFM) and optical microscope images of an $8 \mathrm{~nm}$ thick Bphen film grown by VTE on ITO/MoO $(10 \mathrm{~nm}) / 1: 10$ (by vol.) tetraphenyl-dibenzoperiflanthene (DBP): $C_{70}(60 \mathrm{~nm}$ grown by VTE) and after aging for b) $12 \mathrm{~h}, \mathrm{c}) 25 \mathrm{~h}$, and d) $75 \mathrm{~h}$. e) Similar images of an $8 \mathrm{~nm}$ thick Bphen film grown by VTE on an analogous structure but with the DBP: $C_{70}$ grown to $200 \mathrm{~nm}$ thickness by OVPD and f)-h) after aging for the same durations. The RMS surface roughness of each image is indicated. Thickness scale for the AFM images is provided.
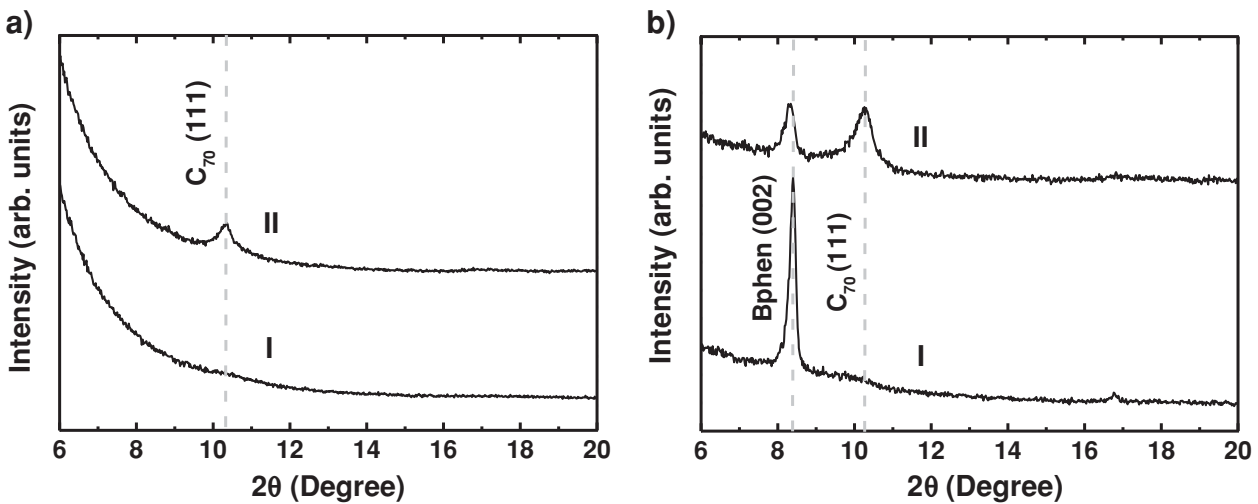

Figure 2. a) Bragg-Brentano Cu-K $\alpha$ XRD measurement of 1:10 (by vol.) DBP: $C_{70}$ (100 nm thick) film grown by I) VTE and II) OVPD on sapphire substrates. b) XRD data of the $50 \mathrm{~nm}$ thick Bphen on the same structure after aging for $75 \mathrm{~h}$. Peak positions and crystal indices are shown.

full width at half maximum of each peak (Table 1), we estimate that the aged Bphen crystallite size is at least 35\% smaller when deposited on an OVPD-grown active layer than on one grown by VTE. Since the $50 \mathrm{~nm}$ thick Bphen layer used for XRD analysis is much greater than that used as a cathode blocker in an OPV (typically $\approx 8 \mathrm{~nm}$ ), the actual differences of Bphen crystallite size might be larger in devices themselves because the reduced thickness enhances pinning by the underlying rough surface.

To understand the relationship between OPV performance and the morphological changes in Bphen, we fabricated three

Table 1. Crystallographic data for Bphen/DBP: $C_{70}$.

\begin{tabular}{|c|c|c|c|c|}
\hline Organic layer & Peak position $\left[{ }^{\circ}\right]$ & FWHM [] & d-Spacing $[\AA ̊]$ & Crystallite size $^{\mathrm{a})}[\mathrm{nm}]$ \\
\hline Bphen (OVPD) & $8.34 \pm 0.03$ & $0.28 \pm 0.02$ & $10.59 \pm 0.04 / 10.57^{b)}$ & $28 \pm 3$ \\
\hline$C_{70}(\mathrm{OVPD})$ & $10.26 \pm 0.03$ & $0.48 \pm 0.02$ & $\left.8.61 \pm 0.03 / 8.60^{c}\right)$ & $16 \pm 2$ \\
\hline Bphen (VTE) & $8.37 \pm 0.03$ & $0.19 \pm 0.02$ & $\left.10.55 \pm 0.04 / 10.57^{b}\right)$ & $42 \pm 4$ \\
\hline
\end{tabular}

a) Calculated using the Scherrer equation, $t=K \lambda / B \cos \theta$ where $K$ is a constant dependent on crystallite shape (0.9), $\lambda$ is the wavelength of Cu-k $\alpha$ X-ray line, $B$ is the full width at half maximum of the peak, and $\theta$ is the Bragg angle; ${ }^{b}$ Calculated based on the (002) plane in orthorhombic Bphen crystal structure; ${ }^{[33]}$ c) $C$ alculated based on the (111) plane in face-centered-cubic (fcc) $C_{70}$ crystal structure. ${ }^{[32]}$ 

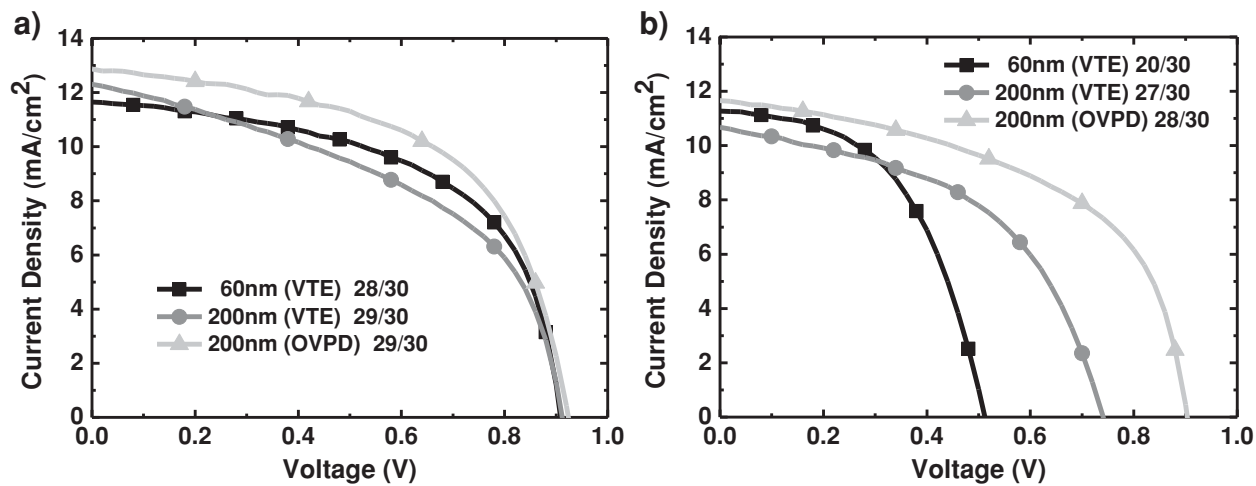

Figure 3. Current density-voltage $(U-V)$ characteristics of DBP: $C_{70}$ mixed heterojunction OPV cells with an $8 \mathrm{~nm}$ thick Bphen blocking layer and a $100 \mathrm{~nm}$ thick Ag cathode. The number of operational devices among the 30 grown on each substrate is specified in the legend. a) Initial $J-V$ characteristics of OPVs with $60 \mathrm{~nm}$ thick and $200 \mathrm{~nm}$ thick VTE-grown active layers, and a $200 \mathrm{~nm}$ thick OVPD-grown active layer. b) J-V characteristics of the three devices after aging $250 \mathrm{~h}$.

devices with the following structures: glass/ITO (indium tin oxide)/1:10 (by vol.) DBP: $C_{70}(60,200 \mathrm{~nm}$ thick grown by VTE and $200 \mathrm{~nm}$ thick grown by OVPD)/Bphen( $8 \mathrm{~nm}$ thick grown by VTE)/Ag(100 nm). In fully VTE-grown devices, 60 and $200 \mathrm{~nm}$ were chosen for the active layer thicknesses- the thinner layer is optimized for VTE-grown devices, whereas the thicker layer corresponds to the highest performance OVPD-grown structures. The OVPD device has a higher fill factor (FF) compared to that grown by VTE at the same thickness $(200 \mathrm{~nm})$, as shown in Figure 3a and Table 2. This difference is due to the low series resistance arising from the $C_{70}$ nanocrystalline morphology in OVPD-grown active layers. ${ }^{[31]}$ After aging for $250 \mathrm{~h}$, the $60 \mathrm{~nm}$ thick VTE-grown device exhibits a substantial drop in $V_{\mathrm{OC}}$, from $0.91 \pm 0.01$ to $0.52 \pm 0.01 \mathrm{~V}$ (Figure $3 \mathrm{~b}$ ) due to the morphological degradation of the blocking layer. The $200 \mathrm{~nm}$ thick VTE-grown device also shows a decrease in $V_{\mathrm{OC}}$ from $0.91 \pm$ 0.01 to $0.74 \pm 0.01 \mathrm{~V}$, whereas the OVPD-grown device exhibits almost no change $\left(V_{\mathrm{OC}}=0.91 \pm 0.01 \mathrm{~V}\right.$ initially, $V_{\mathrm{OC}}=0.89 \pm$ $0.01 \mathrm{~V}$ after aging). In addition, the device yield for the $60 \mathrm{~nm}$ thick VTE-grown population (30 devices) decreases from 93\% to $67 \%$ after $250 \mathrm{~h}$. In contrast, $200 \mathrm{~nm}$ thick devices grown by both VTE and OVPD show only a few shorted devices after aging.

As shown in the fluorescence microscope images in Figure 4, we find that Bphen protrusions pierce the active layer after $75 \mathrm{~h}$

Table 2. Performance of DBP: $C_{70}$ mixed heterojunction OPVs grown by VTE or OVPD.

\begin{tabular}{lcccc}
\hline Active layer thickness & $\begin{array}{c}J_{\mathrm{sc}} \\
{\left[\mathrm{mA} \mathrm{cm}^{-2}\right]}\end{array}$ & $\begin{array}{c}V_{\mathrm{OC}} \\
{[\mathrm{V}]}\end{array}$ & $\mathrm{FF}$ & $\begin{array}{c}\mathrm{PCE} \\
{[\%]}\end{array}$ \\
\hline As-grown & & & & \\
$60 \mathrm{~nm}(\mathrm{VTE})$ & $11.6 \pm 0.02$ & $0.91 \pm 0.01$ & $0.56 \pm 0.01$ & $6.0 \pm 0.2$ \\
$200 \mathrm{~nm}$ (VTE) & $12.3 \pm 0.02$ & $0.91 \pm 0.01$ & $0.48 \pm 0.01$ & $5.3 \pm 0.2$ \\
$200 \mathrm{~nm}$ (OVPD) & $12.9 \pm 0.02$ & $0.91 \pm 0.01$ & $0.56 \pm 0.01$ & $6.7 \pm 0.2$ \\
After 250 h of light illumination & $11.2 \pm 0.02$ & $0.52 \pm 0.01$ & $0.52 \pm 0.01$ & $3.1 \pm 0.02$ \\
$60 \mathrm{~nm}$ (VTE) & $10.7 \pm 0.02$ & $0.74 \pm 0.01$ & $0.49 \pm 0.01$ & $4.0 \pm 0.02$ \\
$200 \mathrm{~nm}$ (VTE) & $11.6 \pm 0.02$ & $0.89 \pm 0.01$ & $0.52 \pm 0.01$ & $5.5 \pm 0.02$ \\
$200 \mathrm{~nm}$ (OVPD) & & & &
\end{tabular}

for the VTE-grown sample. These protrusions contain Ag, identified by three peaks (at $2.98,3.14$, and $3.35 \mathrm{keV}$ ) in the energy dispersive spectra (EDS; see Figure $4 \mathrm{c}$ and Experimental Section). This suggests that device shorts are a result of the diffusion of Ag atoms through the grain boundaries between crystallites in the aged Bphen layer. ${ }^{[34]}$ Such protrusions are completely absent for the OVPD-grown sample (Figure 4b), thus greatly reducing the possibility of shorts.

The decrease in $V_{\mathrm{OC}}$ can be understood using the expression for the open circuit voltage of organic heterojunctions, where $e^{[35]}$

$q V_{\mathrm{OC}}=\Delta E_{\mathrm{HL}}-n_{\mathrm{A}} k_{\mathrm{B}} T \ln \left[J_{0} / J_{\mathrm{sc}}\right]$

with

$\Delta E_{\mathrm{HL}}=\Phi_{\mathrm{a}}+\Phi_{\mathrm{c}}+q V_{\mathrm{bi}}$

Here, $\Delta E_{\mathrm{HL}}$ is the energy difference between the lowest unoccupied molecular orbital of the acceptor $\left(C_{70}\right)$ and the highest occupied molecular orbital of the donor (DBP), $n_{\mathrm{A}}$ is the ideality factor due to charge recombination at traps in the acceptor layer, $k_{\mathrm{B}}$ is Boltzmann's constant, $T$ is the temperature, and $J_{0}$ is the reverse-bias saturation current density. Also, $\Phi_{\mathrm{a}}$ and $\Phi_{\mathrm{c}}$ are the hole and electron injection barriers at the anode and cathode, respectively, and $V_{b i}$ is the built-in potential determined by the difference in contact work functions: ${ }^{[35]}$ i.e., $V_{b i}=W_{a}-W_{c}=0.8 \pm 0.1 \mathrm{~V}$ for the combination of $\mathrm{Ag}$ and ITO. Figure 5 shows the change in capacitance $(C)$-voltage (V) characteristics after $250 \mathrm{~h}$ of aging for the 60 and $200 \mathrm{~nm}$ active-layer-thickness VTE-grown devices, and for the $200 \mathrm{~nm}$ thick OVPD-grown device. Voltage shifts were observed in the forward-bias region after aging: $\Delta V=0.39 \pm 0.03,0.18 \pm 0.02$, and $0.03 \pm 0.01 \mathrm{~V}$, respectively. From Equations (1) and (2), $\Delta V$ can either be due to changes in barrier height, $\Delta \Phi_{c}$, or work function, $\Delta W F_{c}$ after aging since the degradation exists only on the cathode side. From the intercept of a linear plot $1 / C^{2}$ versus $V$ at low voltage, we can easily determine $\Delta V$ during aging. ${ }^{[36]}$ Although the origin of $\Delta V$ is unclear, we observe in all cases that the voltage shift is comparable to the decrease in $V_{\mathrm{OC}}(0.38 \pm 0.01,0.17 \pm 0.01$, and $0.02 \pm 0.01$; c.f. Table 2$)$ of the devices according to Equation (2). 
a)

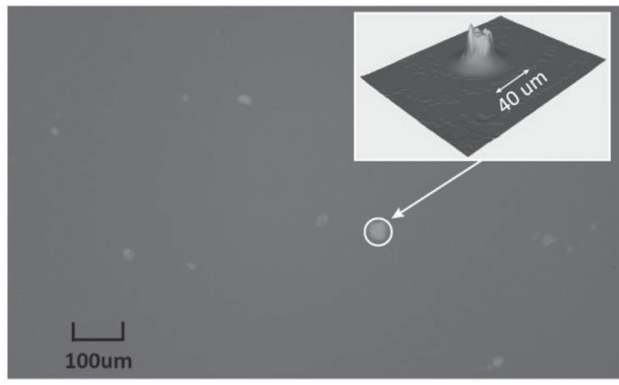

b)

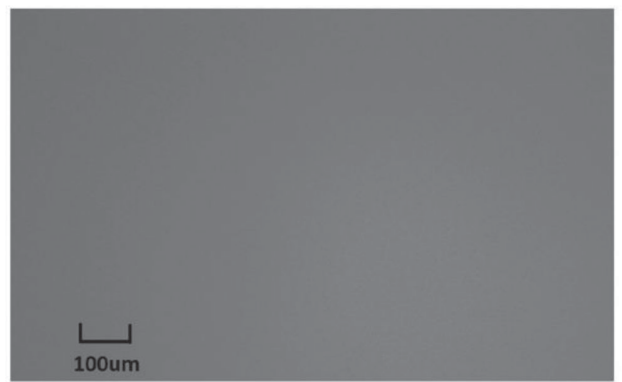

c)

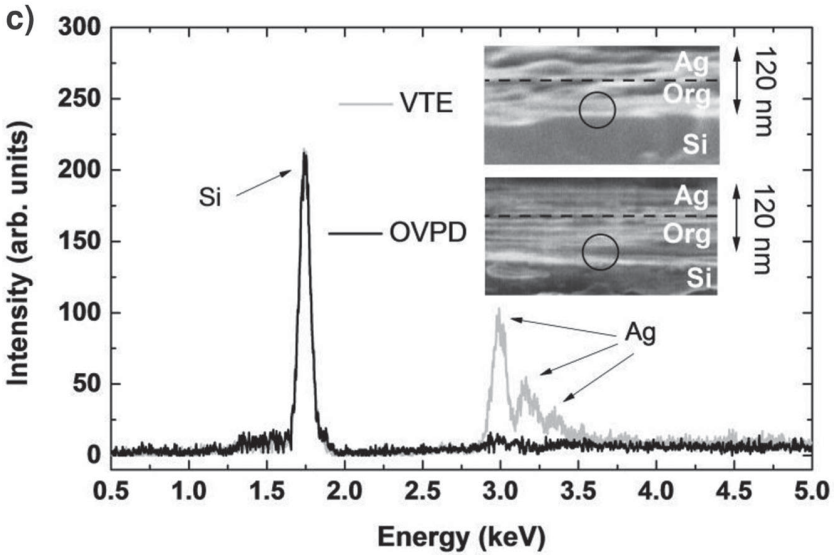

Figure 4. Fluorescence microscope image of glass/12 nm thick tris(8hydroxyquinolinato) aluminum $\left(\mathrm{Alq}_{3}\right) / 1: 10$ (by vol.) $\mathrm{DBP}: \mathrm{C}_{70}(60 \mathrm{~nm})$ grown by a) VTE or b) OVPD/Bphen $(8 \mathrm{~nm}) / \mathrm{Ag}(100 \mathrm{~nm})$ after aging for $75 \mathrm{~h}$. 3D image reconstruction of protrusion (Inset) from multiple slices of the $2 \mathrm{D}$ images is shown. c) Energy dispersive spectra (EDS) of DBP: $C_{70}$ $(60 \mathrm{~nm}$ thick grown by VTE or OVPD)/Bphen $(8 \mathrm{~nm}) / \mathrm{Ag}(60 \mathrm{~nm})$ films on a Si substrate after aging $75 \mathrm{~h}$. Elements corresponding to each peak are indicated. Inset: Cross-sectional SEM images of each sample with the EDS probe area indicated (circle). The probe area is located well below the $\mathrm{Ag} /$ organic interface to ensure that only areas far away from the contact are sampled for the presence of $\mathrm{Ag}$.

Independent of their source, since $\Delta Q=C \Delta V$, the voltage shifts in Figure 5 imply a corresponding change in fixed charge $(\Delta Q)$ at the interfaces between the active layer and blocker. Hence, we infer that interfacial defects caused by morphological irregularities during layer crystallization introduce a substantially higher fixed charge density in the VTE-grown active layers than in those grown by OVPD. These interface states have the highest density in films that undergo the greatest crystallization: $60 \mathrm{~nm}$ thick and $200 \mathrm{~nm}$ thick VTE-grown
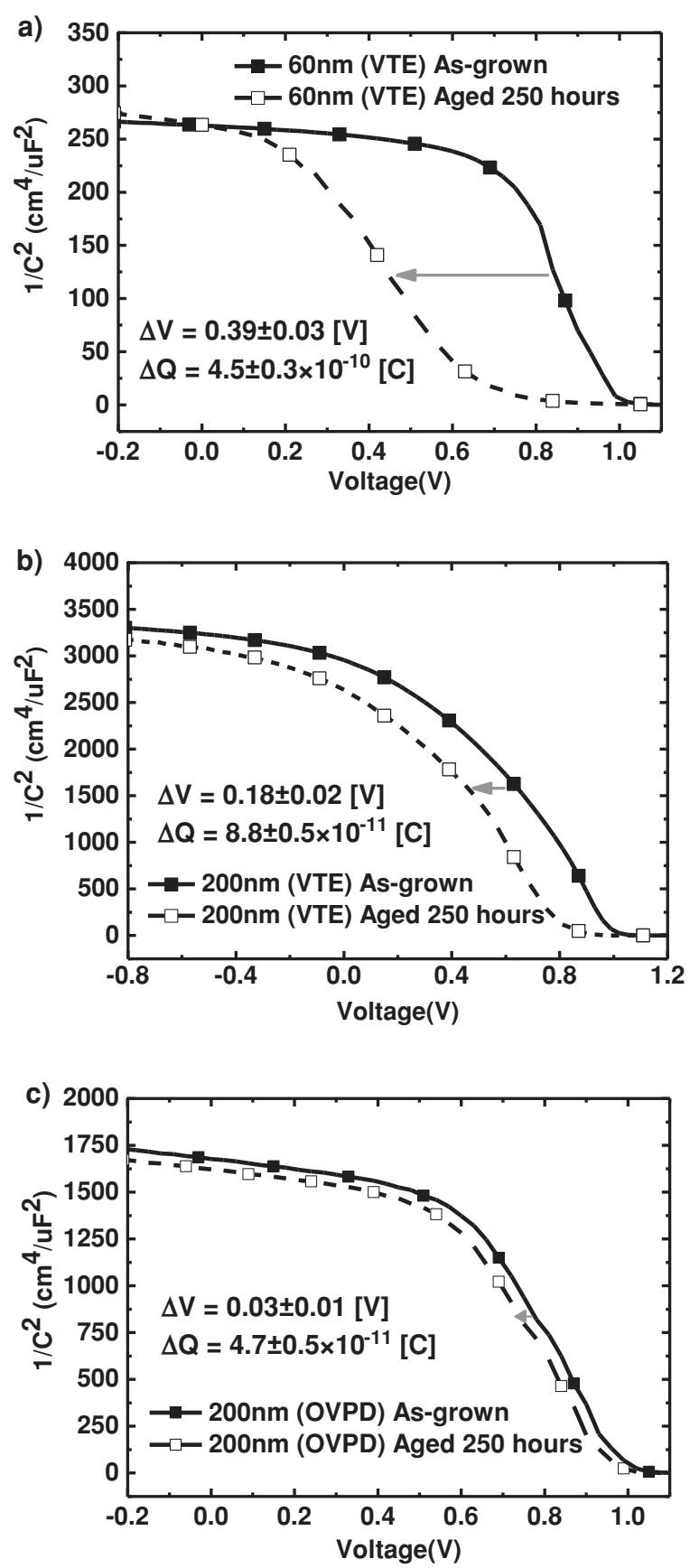

Figure 5. Capacitance-voltage $\left(1 / C^{2}\right.$ vs $\left.V\right)$ characteristics of a) $60 \mathrm{~nm}$ thick VTE-grown, b) $200 \mathrm{~nm}$ thick VTE-grown, and c) $200 \mathrm{~nm}$ thick OVPDgrown DBP: $C_{70}$ active layer devices before and after aging for $250 \mathrm{~h}$. Voltage shifts $(\Delta V)$ are obtained from the voltage difference between the initial curve and one after the aging in the middle of the straight line (grey arrows), from which the change in the fixed charge density $(\Delta Q)$ is inferred.

layers are therefore anticipated to have higher defect densities than $200 \mathrm{~nm}$ thick OVPD-grown layers. Specifically, the $60 \mathrm{~nm}$ thick VTE-grown devices show the largest $\Delta Q=(4.5 \pm 0.3) \times$ $10^{-10} \mathrm{C}$ compared to $\Delta Q=(8.8 \pm 0.5) \times 10^{-11} \mathrm{C}$ for the $200 \mathrm{~nm}$ thick VTE-grown devices and $\Delta Q=(4.7 \pm 0.5) \times 10^{-11} \mathrm{C}$ for the OVPD-grown devices. 
a)

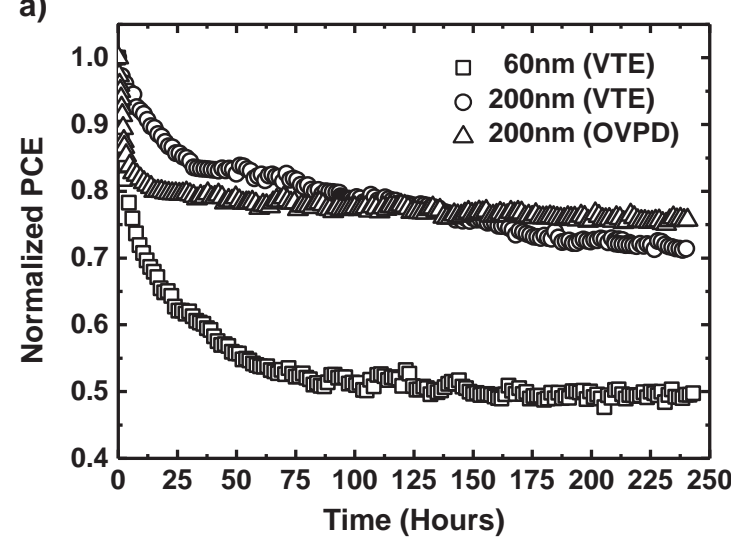

c)

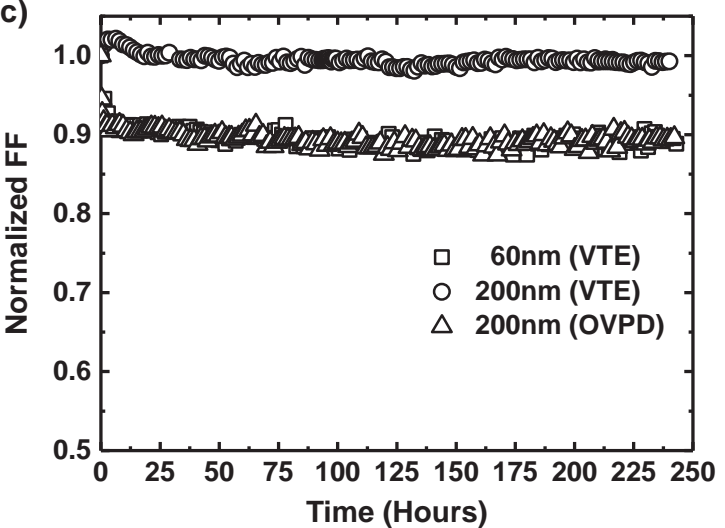

b)

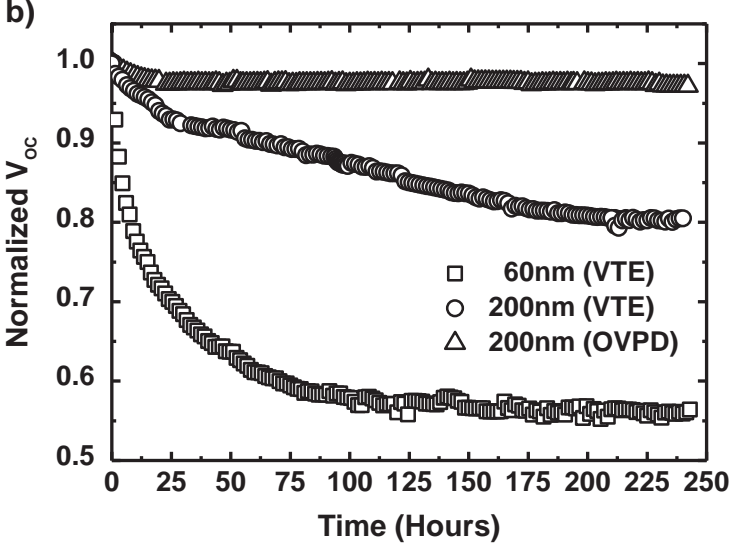

d)

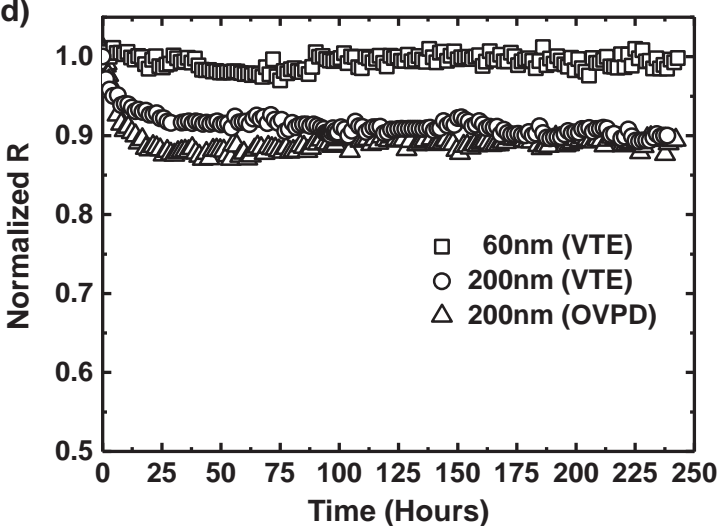

Figure 6. Aging characteristics of three DBP: $C_{70}$ mixed heterojunction devices ( $60 \mathrm{~nm}$ thick, $200 \mathrm{~nm}$ thick active layer grown by VTE, and $200 \mathrm{~nm}$ thick active layer grown by OVPD) with an $8 \mathrm{~nm}$ thick Bphen blocking layer and a $100 \mathrm{~nm}$ thick Ag cathode. The normalized a) power conversion efficiency, PCE, b) open circuit-voltage, $\left.V_{\mathrm{OC}}, \mathrm{c}\right)$ responsivity, $R$, and d) FF over $250 \mathrm{~h}$ of AM $1.5 \mathrm{G}$ illumination are shown.

The decrease in $V_{\mathrm{OC}}$ with device age is the primary source of the decrease in PCE for both VTE-grown devices, as shown in Figure 6. While both VTE-grown devices show monotonic decreases in $V_{\mathrm{OC}}$ versus time, the effect of Bphen morphology more rapidly impacts the thin active layer device performance. In the $200 \mathrm{~nm}$ thick OVPD-grown device, however, both responsivity and $\mathrm{FF}$ decrease by only $11 \% \pm 1 \%$ and $9 \% \pm 1 \%$ from their initial values respectively, during the first $25 \mathrm{~h}$ (corresponding to initial burn-in losses ${ }^{[37]}$. After this, the device performance is stable for the following $225 \mathrm{~h}$, showing a clear distinction from the VTE-grown devices.

In summary, the effect of morphological changes over time of the Bphen blocking layer on device performance was investigated for DBP: $C_{70}$ mixed heterojunction OPVs whose active regions are grown by either VTE or OVPD. The Bphen blocking layer has a tendency to crystallize which results in a decrease in $V_{\mathrm{OC}}$ due to the accumulation of charge at the active-layer/ Bphen interface. Morphological degradation not only affects device performance but also leads to electrical shorts - an effect that is mitigated by growing thicker active layers and is entirely eliminated by the use of OVPD-grown active layers. The rough surface of the nanocrystalline OVPD-grown active layer pins the Bphen morphology, thereby hindering its transformation. This, in turn, results in OPVs that maintain both a high $V_{\mathrm{OC}}$ and yield after $250 \mathrm{~h}$ of operation.

\section{Experimental Section}

Atomic force microscope images were obtained using a Bruker Dimension Icon AFM in the tapping mode. XRD patterns were obtained in the Bragg-Brentano configuration on organic films deposited on sapphire substrates. Fluorescence microscope images were recorded with an Olympus BX-61 motorized microscope for the following structures: Glass/12 nm thick tris(8-hydroxyquinolinato) aluminum $\left(\mathrm{Alq}_{3}\right) / 1: 10$ (by vol.) DBP: $C_{70}(60 \mathrm{~nm}$ grown by either VTE or OVPD)/ Bphen $(8 \mathrm{~nm}) / \mathrm{Ag}(100 \mathrm{~nm})$. The thickness of the fluorescent $\left(\mathrm{Alq}_{3}\right)$ layer was adjusted until sufficient contrast between the protrusions and the fluorescence background emission was clearly observed. Scanning electron microscope (SEM) images were acquired using a Hitachi SU8000 in-line SEM equipped with an energy dispersive spectrometry (EDS) microprobe at $10 \mathrm{kV}$. The cross-sectional images were acquired on layers consisting of 1:10 (by vol.) DBP: $C_{70}(60 \mathrm{~nm}$ grown by either VTE or OVPD) $/ \mathrm{Ag}(60 \mathrm{~nm})$ deposited on Si substrates. The samples were cleaved after aging. The $\mathrm{Ag}$ and organic bulk layers were distinguished from the Si substrate using EDS. Samples were aged under simulated AM1.5C illumination in an ultra-high purity $\left(\mathrm{H}_{2} \mathrm{O}, \mathrm{O}_{2}<1 \mathrm{ppm}\right) \mathrm{N}_{2}$-filled glovebox. Intensity was calibrated using a National Renewable Energy Laboratory (NREL)-traceable KG-5 filtered Si reference cell.

OPV cells were prepared as follows. $2.5 \mathrm{~cm}^{2}$ square glass substrates were prepatterned with rectangular, $150 \mathrm{~nm}$ thick ITO patterns for each contact. The substrates were subsequently cleaned in tergitol, deionized water, twice with acetone, and twice with isopropanol for $>5 \mathrm{~min}$ each. Ultraviolet-ozone treatment was applied for $10 \mathrm{~min}$ followed by $1 \mathrm{~min}$ snow-cleaning ${ }^{[38]}$ with $\mathrm{CO}_{2}$. Substrates were transferred to the glovebox, and a shadow mask with $1.2 \mathrm{~cm}^{2}$ square openings was aligned to the 
ITO pattern for deposition of all layers except the cathode. Both $\mathrm{MoO}_{3}$ and Bphen were deposited at $1 \AA \mathrm{s}^{-1}$ in a VTE chamber (base pressure $\approx 10^{-7}$ torr). Thicknesses and deposition rates were monitored using quartz crystal monitors. DBP and $C_{70}$ were coevaporated at $0.2,2.0 \AA \mathrm{s}^{-1}$, leading to 1:10 volume ratio. The OVPD growth employed a multibarrel quartz reactor with a $10 \mathrm{sccm}$ (standard cubic centimeters per minute) $\mathrm{N}_{2}$ flow used in each source barrel along with a $6 \mathrm{sccm}$ dilution flow in the main reactor tube, maintained at a pressure of 0.28 torr. The DBP barrel was heated to $375 \pm 2{ }^{\circ} \mathrm{C}$, and the $C_{70}$ barrel to $520 \pm 2{ }^{\circ} \mathrm{C}$ inside the reactor having three temperature zones of 560,500 , and $440{ }^{\circ} \mathrm{C}$ to reach the same deposition rate as in VTE growth. A shadow mask was aligned to the anode patterns to define a $2 \mathrm{~mm}^{2}$ device area via the deposition of the $\mathrm{Ag}$ cathode by VTE at $1 \AA \mathrm{s}^{-1}$. Following deposition, the devices were packaged in an ultrahigh purity $N_{2}$ environment by sealing a $1.6 \mathrm{~cm}^{2}$ cover glass to the substrate using UV-curable epoxy applied along its periphery.

Current density $(U)$ versus $V$ characteristics were measured under AM1.5C illumination using an Agilent $4156 \mathrm{C}$ parameter analyzer. Additionally, the wavelength-dependent external quantum efficiency (EQE) was recorded using a fiber-coupled Xe arc lamp at $200 \mathrm{~Hz}$ with a Stanford SR830 DSP lock-in amplifier. Then the short circuit current density, $J_{\mathrm{sc}}$, was calculated by integrating the EQE over the AM $1.5 \mathrm{C}$ solar spectrum. The intensity of the solar simulator was set such that $J_{\mathrm{sc}}$ was equal to that obtained from the integrated EQE. The measured and calculated $J-V$ agree to within $4 \%$. Capacitance-voltage characteristics were obtained using an HP 4284A precision LCR meter equipped with an Agilent B1500A semiconductor device analyzer. A $25 \mathrm{mV}$ amplitude AC signal at $1 \mathrm{kHz}$ frequency was applied.

The encapsulated devices were aged at $50 \pm 5{ }^{\circ} \mathrm{C}$ under a large area $\left(210 \mathrm{~mm}^{2}\right)$ AM 1.5G Xe arc lamp solar simulator. The $J-V$ characteristics of each device were automatically acquired every $30 \mathrm{~min}$ using a computer-controlled semiconductor parameter analyzer.

\section{Acknowledgements}

The authors gratefully acknowledge Mr. Hyunsoo Kim and Dr. Cedric Rolin for useful discussions. This work was partially supported by the SunShot Program of the US Department of Energy (Energy Efficiency and Renewable Energy) under award number DE-EE0005310 (B.S., experiment, analysis, Q.C.B., lifetime measurement) and NanoFlex Power Inc (S.R.F., experimental direction, analysis).

Received: November 3, 2014

Revised: December 22, 2014

Published online: January 21, 2015

[1] W. Zeng, K. S. Yong, Z. M. Kam, F. Zhu, Y. Li, Appl. Phys. Lett. 2010, 97, 133304.

[2] O. P. Lee, A. T. Yiu, P. M. Beaujuge, C. H. Woo, T. W. Holcombe, J. E. Milestone, J. D. Douglas, M. S. Chen, J. M. J. Frechet, Adv. Mater. 2011, 23, 5359.

[3] Y. Zhou, T. Taima, T. Miyadera, T. Yamanari, M. Kitamura, K. Nakatsu, Y. Yoshida, Appl. Phys. Lett. 2012, 100, 233302.

[4] J. D. Zimmerman, B. E. Lassiter, X. Xiao, K. Sun, A. Dolocan, R. Gearba, D. a Vanden Bout, K. J. Stevenson, P. Wickramasinghe, M. E. Thompson, S. R. Forrest, ACS Nano 2013, 7, 9268.

[5] J. S. Kim, J. H. Park, J. H. Lee, J. Jo, D.-Y. Kim, K. Cho, Appl. Phys. Lett. 2007, 91, 112111.

[6] J. M. Szarko, J. Guo, Y. Liang, B. Lee, B. S. Rolczynski, J. Strzalka, T. Xu, S. Loser, T. J. Marks, L. Yu, L. X. Chen, Adv. Mater. 2010, 22, 5468.
[7] B. Ray, M. A. Alam, Sol. Energy Mater. Sol. Cells 2012, 99, 204.

[8] S. Bertho, G. Janssen, T. J. Cleij, B. Conings, W. Moons, A. Gadisa, J. D'Haen, E. Goovaerts, L. Lutsen, J. Manca, D. Vanderzande, Sol. Energy Mater. Sol. Cells 2008, 92, 753.

[9] M. F. Lo, T. W. Ng, S. L. Lai, F. L. Wong, M. K. Fung, S. T. Lee, C. S. Lee, Appl. Phys. Lett. 2010, 97, 143304.

[10] T. Y. -H. Lee, Q. Wang, J. U. Wallace, S. H. Chen, J. Mater. Chem. 2012, 22, 23175

[11] C. H. Peters, I. T. Sachs-Quintana, J. P. Kastrop, S. Beaupré, M. Leclerc, M. D. Mcgehee, Adv. Energy Mater. 2011, 1, 491.

[12] F. C. Krebs, Stability and Degradation of Organic and Polymer Solar Cells, Wiley, Chichester, UK 2012.

[13] M. Shtein, P. Peumans, J. B. Benziger, S. R. Forrest, J. Appl. Phys. 2003, 93, 4005.

[14] F. Yang, M. Shtein, S. R. Forrest, J. Appl. Phys. 2005, 98, 014906.

[15] F. Yang, M. Shtein, S. R. Forrest, Nat. Mater. 2004, 4, 37.

[16] S. R. Forrest, Nature (London) 2004, 428, 911.

[17] M. Schwambera, N. Meyer, M. Gersdorff, M. Reinhold, G. Strauch, R. Beccard, M. Heuken, SID Symp. Dig. Tech. Pap. 2003, 34, 1419.

[18] J. Kreis, M. Schwambera, D. Keiper, M. Gersdorff, M. Long, M. Heuken, Proc. SPIE 2012, 8476, 84761L.

[19] R. R. Lunt, B. E. Lassiter, J. B. Benziger, S. R. Forrest, Appl. Phys. Lett. 2009, 95, 233305.

[20] C. Rolin, K. Vasseur, J. Genoe, P. Heremans, Org. Electron. 2010, 11, 100

[21] T. X. Zhou, T. Ngo, J. J. Brown, M. Shtein, S. R. Forrest, Appl. Phys. Lett. 2005, 86, 021107.

[22] J. Y. Kim, T. Yasuda, Y. S. Yang, C. Adachi, Adv. Mater. 2013, 25, 2666.

[23] T. Zhang, B. Chu, W. Li, Z. Su, Q. M. Peng, B. Zhao, Y. Luo, F. Jin, X. Yan, Y. Gao, H. Wu, F. Zhang, D. Fan, J. Wang, ACS Appl. Mater. Interfaces 2014, 6, 11907.

[24] X. Xiao, J. D. Zimmerman, B. E. Lassiter, K. J. Bergemann, S. R. Forrest, Appl. Phys. Lett. 2013, 102, 073302.

[25] O. L. Griffith, S. R. Forrest, Nano Lett. 2014, 14, 2353.

[26] H. Kanno, R. J. Holmes, Y. Sun, S. Kena-Cohen, S. R. Forrest, Adv. Mater. 2006, 18, 339

[27] J. H. Seo, J. H. Seo, J. H. Park, Y. K. Kim, J. H. Kim, G. W. Hyung, K. H. Lee, S. S. Yoon, Appl. Phys. Lett. 2007, 90, 203507.

[28] B. W. D'Andrade, S. R. Forrest, A. B. Chwang, Appl. Phys. Lett. 2003 83, 3858.

[29] M. Tavakkoli, R. Ajeian, M. N. Badrabadi, S. S. Ardestani, S. M. H. Feiz, K. E. Nasab, Sol. Energy Mater. Sol. Cells 2011, 95, 1964.

[30] P. Kathirgamanathan, S. Surendrakumar, S. Ravichandran, R. R. Vanga, J. Antipan-Lara, S. Ganeshamurugan, M. Kumaravel, G. Paramaswara, V. Arkley, Chem. Lett. 2010, 39, 1222.

[31] B. Song, C. Rolin, J. D. Zimmerman, S. R. Forrest, Adv. Mater. 2014, 26, 2914.

[32] M. Valsakumar, N. Subramanian, M. Yousuf, P. Sahu, Y. Hariharan, a Bharathi, Sankara Sastry V, J. Janaki, G. Rao, T. Radhakrishnan, C. Sundar, Phys. Rev. B: Condens. Matter 1993, 48, 9080.

[33] H. Li, J.-L. Brédas, C. Lennartz, J. Chem. Phys. 2007, 126, 164704.

[34] F. C. Krebs, K. Norrman, Prog. Photovoltaics Res. Appl. 2007, 15, 697.

[35] N. C. Giebink, G. P. Wiederrecht, M. R. Wasielewski, S. R. Forrest, Phys. Rev. B 2010, 82, 155305.

[36] T. Kirchartz, W. Gong, S. A. Hawks, T. Agostinelli, R. C. I. MacKenzie, Y. Yang, J. Nelson, J. Phys. Chem. C 2012, 116, 7672.

[37] X. Tong, N. Wang, M. Slootsky, J. Yu, S. R. Forrest, Sol. Energy Mater. Sol. Cells 2013, 118, 116.

[38] N. Wang, J. D. Zimmerman, X. Tong, X. Xiao, J. Yu, S. R. Forrest, Appl. Phys. Lett. 2012, 101, 133901. 